\title{
Analise dos parcelamentos de solo urbano no município de dois vizinhos
}

Analysis of urban soil installments in two neighbors municipality

Análisis de plazos suelo urbano en dos vecinos municipio

Daise Martinazzo

Especialista, UNIPAR, Brasil

Daise_martinazzo@hotmail.com

\section{Lucas Gabriel Winter}

Mestrando, UTFPR, Brasil

Igwinter@hotmail.com

Vanessa Franciele de Gois

Especialista, IAHCS, Brasil arquiteturaurb.vanessa@gmail.com 
RESUMO

A preocupação com a forma que as cidades estão se expandindo é cada vez mais intensa. As direções e condicionantes em que elas se ordenam, influenciam na vida útil, na paisagem e na funcionalidade do meio. Entendemos que os órgãos responsáveis devem estar cientes na importância da integração dos espaços urbanos com o eco sistema, sem deixar de lado a compreensão do parcelamento do solo urbano, também se faz necessário efetuar e promover o bem estar coletivo, sem causar danos à natureza. Este artigo tem como fundamento analisar e compreender como são executadas as áreas de expansão urbana através do parcelamento de solo no município de Dois Vizinhos - Pr. Com base neste estudo, será avaliada a maneira de sua aplicação, se estão coerentes com a legislação local, estadual e federal, bem como quais os métodos utilizados para estes locais desempenharem características da sustentabilidade, com infraestrutura adequada e cumprindo com a sua função social. Assim, apontaremos algumas sugestões para melhor aproveitamento de áreas residenciais.

PALAVRAS-CHAVE: Expansão Urbana; Loteamentos; Legislação; Parcelamento de Solo Urbano.

\section{SUMMARY}

The concern with the way that cities are expanding is increasingly intense. Directions and conditions in which they are ordered, influence the life in the countryside and in the middle functionality. We understand that responsible agencies should be aware of the importance of integration of urban spaces with the eco system, without leaving aside the understanding of the urban land division, it is also necessary to carry out and promote the collective wellbeing, without causing damage to nature. This article is based analyze and understand how to run the areas of urban expansion through the soil installment in the municipality of Two Neighbors - Pr. Based on this study, the manner of its application will be evaluated if they are consistent with local law, state and federal, and which methods were used for these sites perform sustainability characteristics, with adequate infrastructure and fulfilling its social function. So, we consider some suggestions for better use of residential areas.

KEYWORDS: Urban expansion; allotments ; Legislation; Urban Land Installment .

\section{RESUMEN}

La preocupación por la forma en que las ciudades se están expandiendo cada vez más intensa. Las direcciones y las condiciones en las que están clasificadas, influyen en la vida en el campo y en la funcionalidad media. Entendemos que los organismos responsables deben ser conscientes de la importancia de la integración de los espacios urbanos con el sistema ecológico, sin dejar de lado la comprensión de la división del suelo urbano, también es necesario llevar a cabo y promover el bienestar colectivo, sin causar daño a la naturaleza. Este artículo se basa analizar y comprender cómo ejecutar las áreas de expansión urbana a través de la entrega de suelo en el municipio de Dos Vecinos - Pr. Sobre la base de este estudio, se evaluará la forma de su aplicación si son coherentes con la legislación local, métodos estatales y federales, y que fueron utilizados para estos sitios realizan características de sostenibilidad, con una infraestructura adecuada y el cumplimiento de su función social. Por lo tanto, tenemos en cuenta algunas sugerencias para un mejor uso de las zonas residenciales.

PALABRAS CLAVE: La expansión urbana ; adjudicaciones ; legislación; Cuota suelo urbano. 


\section{INTRODUÇAO}

O objeto de estudo deste trabalho está sendo muito debatido na atualidade por estar relacionado ao bem estar dos habitantes em seu meio. Este bem estar é efetuado através de planejamento das cidades e em conjunto com Leis Federais, Estaduais e Municipais, com objetivo de organizar, a fim de evitar problemas futuros, como crescimento desordenado, prejuízo no fluxo viário, falta de infraestrutura, etc.

Através deste, vamos demonstrar como estão sendo realizados os parcelamentos de solo na cidade de Dois Vizinhos - PR, indicando os principais problemas neles encontrados e trazendo soluções coerentes para cada situação.

Podemos destacar que a cidade de Dois Vizinhos está em constante crescimento populacional, sendo constatado pelo IBGE que em 2010 a população era de 36.179 habitantes e a previsão para o ano de 2015 foi uma população de 39.138 habitantes, isto é, um aumento significativo de $7.77 \%$ na população, crescendo mais que a estimativa do país que fica em $6,67 \%$.

Diante deste diapasão, devemos seguir em defesa da população, que muitas vezes não observam a má intenção do mercado imobiliário, que fazem parcelamentos de solo pensando apenas no retorno lucrativo e deixando de lado todo o equilíbrio ecológico e a função socioambiental da propriedade.

\section{OBJETIVOS}

Demonstrar como é elaborado o parcelamento de solo no município, quais os critérios utilizados, observando se a forma como é proposto esta de acordo com os princípios sustentáveis prevendo bem estar social.

\section{METODOLOGIA}

A analise fundou-se através de levantamento de dados, artigos científicos envolvendo o tema, identificando os objetivos pelos quais se desenvolveu o trabalho. Realizaram-se observações in loco com base em conhecimentos específicos, para compreender o desenvolvimento e a aplicação do parcelamento. Utilizou-se de um questionário com funcionário do setor de planejamento com finalidade de compreender quais os critérios e qual processo é utilizado no município para a aprovação da expansão.

\section{CONTEXTO DE LOCALIZAÇÃO E ECONOMIA}

A cidade de Dois Vizinhos - PR, esta localizada ao norte do Sudoeste do Paraná, considerada do interior do Estado, pertence a microrregião de Francisco Beltrão - PR, situada a quatrocentos e cinquenta quilômetros da capital do Estado, Curitiba - PR. 


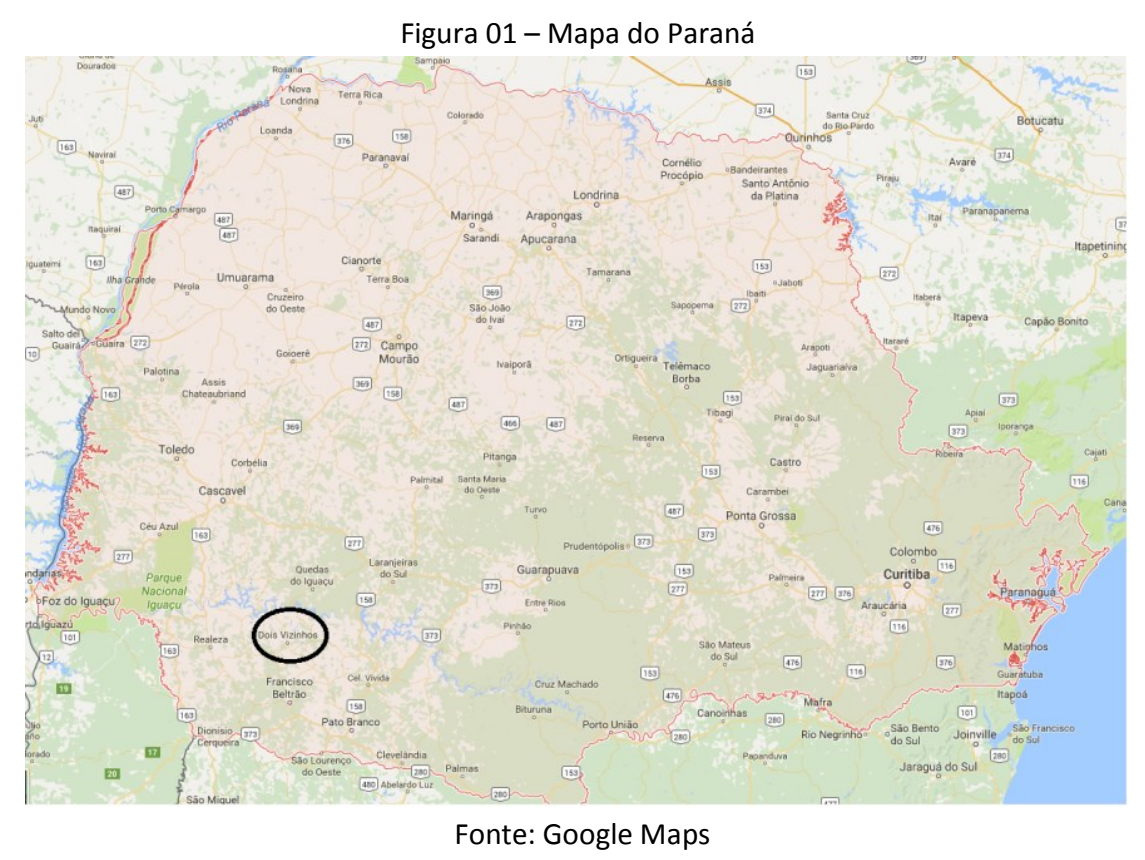

Tem como maior fator econômico a avicultura, conquistando em 2005 o título de Capital Nacional do Frango, por abater mais de meio milhão de aves/dia, sendo a maior empregadora direta e indireta de mão de obra da cidade, hoje conhecida nacionalmente de BRFood's.

O fator econômico acima destacado e as faculdades instaladas nela são os principais responsáveis pelo aumento populacional, surgindo também com mais ênfase o aumento demográfico, assim consequentemente houve a necessidade de novos parcelamentos de solos para atender esta demanda.

\section{PLANEJAMENTO DOS ESPAÇOS URBANOS}

O desenvolvimento urbano deve ser executado pelo município, com objetivo de garantir o bem estar dos habitantes, e através de diretrizes gerais fixadas em leis ordenando o desenvolvimento das funções sociais da cidade (MOTTA, pag. 24 e 25).

Um dos fatores importantes é o Plano Diretor, um instrumento básico da política de expansão urbana. Através dela que o município deve resguardar os direitos a melhoria das condições de vida população, realizando a composição dos espaços e planejando para que suas modificações não atrapalhem o desenvolvimento das futuras gerações e traga uma melhoria na qualidade de vida.

Os espaços são direcionados a partir das leis de zoneamento que se referem na partilha do território municipal, com a destinação da terra, uso e ocupação do solo.

Sob estes aspectos, demarcamos as áreas em zonas:

- Urbana - designada a edificações residenciais, comerciais ou industriais, providas por serviços públicos (infraestrutura), iluminação, pública, água, esgoto, viária, calçadas, espaços comunitário como parques, cultura, lazer, escolar, saúde e etc.

- Expansão urbana - área de atividades rurais e destinadas a uma reserva para expansão urbana em estimativa de 20 anos, (parcelamentos de solo); 
- Urbanização específica - que será uma área destinada a uso do poder publico;

- Rural - não urbanizada;

- Uso do solo controle da ocupação do solo.

Sendo assim, quando a cidade ja está saturada, inicia-se o processo de loteamentos para expansão, muito comentadas nos últimos anos pelo crescimento populacional, estes novos espaços devem ser previstos e planejados pelo plano diretor municipal e o estatuto da cidade.

\title{
5.1 LOTEAMENTOS URBANOS
}

Um dos principais responsáveis pela expansão territorial da zona urbana são os loteamentos urbanos. Eles são delineados e seguem critérios elencados pela legislação municipal estadual e federal, com acompanhamento do setor de planejamento, profissionais de engenharia e arquitetura para que aconteça nos padrões destinados pelas leis.

Observando o conceito utilizado pelo professor Hely Lopes Meirelles, assim descreve como:

\begin{abstract}
Loteamento é meio de urbanização e só se efetiva por procedimento voluntário e formal do proprietário da gleba, que planeja a sua divisão e a submete à aprovação da Prefeitura, para subsequente inscrição no registro imobiliário, transferência gratuita das áreas das vias públicas e espaços livres ao Município, e a limitação dos lotes. ${ }^{1}$
\end{abstract}

Os loteamentos são instituídos em solo, definidas como zonas urbanas de expansão ou de urbanização específica pelo plano diretor da cidade, determinam também o caráter mínimo necessário para o parcelamento do solo, as condições que o empreendedor/loteador e o responsável técnico devem estabelecer no planejamento do loteamento. Ambos devem demonstrar em projeto e determinar todas as áreas de preservação, infraestrutura, usos e zoneamentos propostos para funcionar sem conflitos, e apresente condições de receber unidades habitacionais, comerciais e industriais.

Um parcelamento com integridade prevê o bem estar coletivo, seguindo as leis determinadas e a valorização natural do local onde está sendo inserido. Portanto deve-se desenvolver os estudos necessários para receber o impacto do empreendimento no local, ainda observando as alterações de fluxos do tráfego, condições de ventilação, alagamentos e todas as exigências pela qual o estudo de impacto de vizinhança destaca.

Sem um estudo aprofundado do local, vários erros ocorreram e os indivíduos que adquirirem esses lotes saíram em prejuízo, pois os empreendedores não estão preocupados com o bem estar dos ocupantes, mas sim com o lucro que pode gerar.

Assim, fica claro e evidente a importância deste estudo, realizando uma análise técnica para chegar a um resultado dos reflexos positivos e negativos do empreendimento, e qual a maneira mais satisfatória de seu planejamento e inserção.

\footnotetext{
${ }^{1}$ Hely Lopes Meirelles, in Urbanismo e Proteção Ambiental. RDP n.o 39/40, ERT, São Paulo: 1976, p 62.
} 


\subsection{DESENVOLVIMENTO SUSTENTÁVEL DE PARCELAMENTO URBANO}

O conceito vem oferecer uma infraestrutura preparada, permitindo sanar as necessidades dos moradores, compreendendo que o desenvolvimento sustentável estende-se a várias áreas, definindo um ponto de equilíbrio entre o crescimento econômico, igualdade social e a proteção do ambiente.

Em países de terceiro mundo o desenvolvimento sustentável não tem produzido muitas atuações, mesmo tendo consciência da importância deste assunto, ainda visam lucro. A contaminação do solo, rios e ar são problemas ambientais habituais no país.

A sustentabilidade urbana é um debate que surge da necessidade de entendermos o conjunto de problemas da qualidade de vida urbana, tais como: alterações climáticas, esgotamento de energias fósseis e minerais, desmatamento desenfreado, violência, desigualdade social, transporte público escasso, entre outros. São inúmeras as questões levantadas nesse contexto, assim como a pluralidade com que o termo é empregado na literatura e documentos, pois, além da discussão urbana inserida na dimensão ambiental, o conceito incorpora as dimensões econômica, social, cultural e política. (SAMPAIO, 2009.) ${ }^{2}$

Existem duas características para desenvolvimento do parcelamento do solo a Urbanização Dispersa a qual não são desenvolvidos os princípios básicos para incorporação da sustentabilidade, onde surgem fora dos perímetros urbanos da cidade e o novo urbanismo que tenda resgatar a qualidade de vida correlacionando meio ambiente com as estruturas das cidades (IARA NEGREIROS, 2009).

Os princípios básicos seriam o fornecimento de agua, esgoto e energia. Criação de corredores ecológicos para que ocorra o fluxo gênico, observando a preservação do meio ambiente e garantindo a qualidade de vida daquelas pessoas que morram naquela localidade (COMURB, 2013).

Figura 02 - Comparação de aspectos e características da urbanização dispersa e do novo urban
\begin{tabular}{|c|c|}
\hline URBANIZAÇÄO DisPFRSA & NOVO URBANISMO \\
\hline Dispersão & $\begin{array}{c}\text { Compacidade, melhor aproveitamento } \\
\text { e uso do espaço }\end{array}$ \\
\hline $\begin{array}{c}\text { Expansão em áreas rurais ou naturais, } \\
\text { conurbação }\end{array}$ & $\begin{array}{c}\text { Revitalização de áreas previamente } \\
\text { urbanizadas }\end{array}$ \\
\hline $\begin{array}{c}\text { Aumento nas distâncias e viagens percorridas } \\
\text { por automóveis }\end{array}$ & $\begin{array}{c}\text { Projeto amigável ao pedestre e ciclista, ênfase } \\
\text { em transporte coletivo }\end{array}$ \\
\hline $\begin{array}{c}\text { Cidades-dormitório, predominantemente } \\
\text { residenciais }\end{array}$ & Mix de usos, diversidade de usos \\
\hline
\end{tabular}

Fonte: lara Negreiros, 2009

\footnotetext{
${ }^{2}$ Disponível em:

http://www.iau.usp.br/pesquisa/grupos/habis/biblioteca/digital/artigos/sustentabilidade/Artigo_ELECS 2009_Sustentabilidade\%20Urbana_conceitos\%20e\%20controversas_Sampaio.pdf
} 
Para um crescimento ordenado e sem agressão aos nossos recursos naturais o que está escasso, a grande importância no planejamento de cada passo da expansão territorial das cidades que seja prevista e executada de acordo com o Plano Diretor e Estatuto da cidade assim entendem-se que "aquele que atende ás necessidades do presente sem comprometer a possibilidade de gerações futuras atenderem suas próprias necessidades" (MOTTA, 1999).

\section{DEFINIÇÕES DE PARCELAMENTO DE SOLO SOLICITADOS PELO MUNICÍPIO}

Para elaboração do parcelamento do solo é necessário seguir um protocolo no qual será desenvolvido o processo de trâmite legal das etapas, desempenhando cumprimento da legislação.

Para iniciar a implantação de um loteamento, o loteador deverá obter perante a Prefeitura a certidão de diretrizes para uso, ocupação e parcelamento do solo. Assim, devera seguir o que expressa o conforme artigo 6으, da Lei 6.766/79, através da certidão de diretrizes deverá indicar "o uso do solo, traçado dos lotes, do sistema viário, dos espaços livres e das áreas reservadas para equipamentos urbanos e comunitários". (FERNANDES, 2015)

Com a expedição de diretrizes pelo Município, o loteador apresenta o projeto de implantação do loteamento contendo os desenhos, o memorial descritivo e o cronograma de execução de obras com duração máxima de quatro anos, sob pena de caducidade. Com a conclusão das obras, será emitido o "Termo de Verificação de Execução de Obras TVEO" declarando a conclusão das obras de acordo com a certidão de diretrizes e o projeto encaminhado à Municipalidade. O projeto deverá ser instruído com a cópia atualizada da matrícula do imóvel, da certidão negativa de tributos municipais e do instrumento de garantia à Municipalidade, e de eventuais outros documentos solicitados caso a caso pela Prefeitura. (FERNANDES, 2015)

Ainda, apos esse procedimento, é encaminhado ao IAP, para obter um parecer favorável ou não para a autorização deste loteamento. Não será autorizado, caso não siga as medidas adequadas que devem ser deixadas de margem de rios, APP (Área de Preservação Permanente) entre outros. Desta forma, o loteador deverá fazer algumas mudanças para que seja aprovado pelo órgão acima mencionado.

O loteador só poderá registrar o projeto de implantação do loteamento no Cartório de Registro de Imóveis quando a prefeitura aprovar definitivamente. O registro deverá ocorrer no prazo de 180 dias, sob pena também de caducidade da aprovação do projeto. (FERNANDES, 2015).

Outro fator importante salientar que a alienação dos lotes apenas poderá ser feita após o registro do loteamento no Cartório de Registro de Imóveis, sendo proibida a venda de lotes, conforme artigo 37, da Lei 6.766/79.

Será considerado clandestino o loteamento iniciado com parcelamento de solo sem a prévia autorização da prefeitura, ou ainda, inicie as obras com autorização da Municipalidade, sem registrar o loteamento no respectivo Cartório de Registro de Imóveis, ou não execute todas as obras, ou de forma insatisfatória, o loteamento será considerado irregular. 


\section{RESULTADOS E DISCUSSÕES}

Diante destas observações, desenvolvemos um levantamento de dados em quatro loteamentos da cidade de Dois Vizinhos - PR, onde foi observado a falta do princípio de desenvolvimento sustentável, elaborados pelo simples fato de habitação e comercialização de lotes. Também realizamos uma entrevista com o Responsável Técnico pelo Setor de Planejamento Urbano, Sr. Rogerio Luís Nunes, que sanou algumas dúvidas quanto ao desenvolvimento e cobrança municipal para a criação destes novos loteamentos.

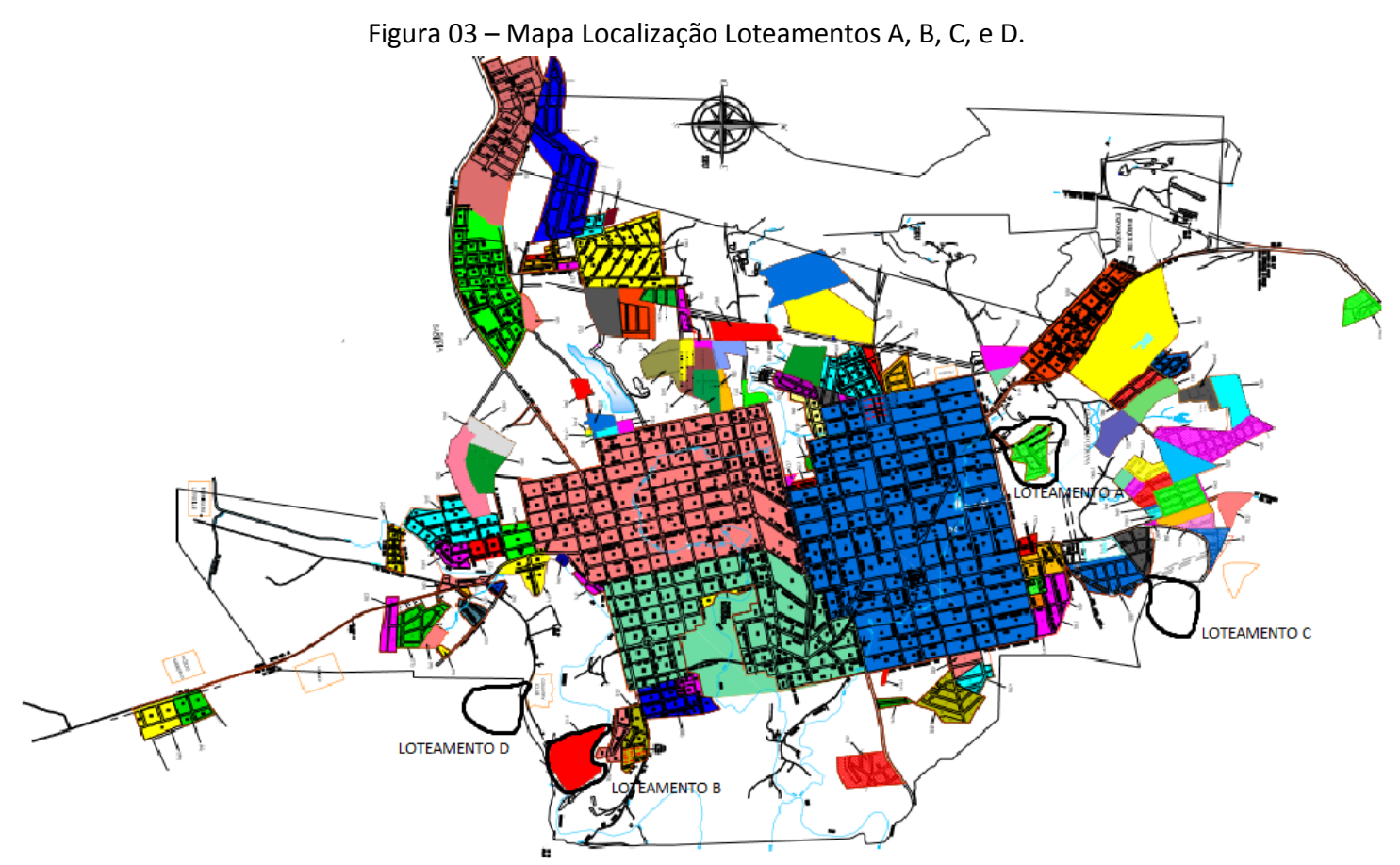

Fonte: doisvizinhos.pr.gov.br

Interessante observar, que nos loteamentos mais antigos, loteadores e profissionais técnicos responsáveis, não deram importância ao bem estar coletivo, pois até hoje a infraestrutura não é adequada. Destacamos isso, pois na maioria deles não possui rede de esgoto, ficando esse sistema intercalado em sua maioria no centro da cidade.

Outro fator importante, é que estes loteamentos não foram desenvolvidos na integração do meio ambiente com a estrutura. Se fosse pensada conforme o novo urbanismo, melhoraria o visual da paisagem urbana.

Observamos acessos não organizados pelo sistema viário já existente, tendo características de condomínio fechado, contendo apenas uma entrada e saída, nem continuidade das vias, seguimentos de metragens de larguras das vias, não caracterizando uma integração destes locais com o meio urbano (exemplo loteamento " $A$ ", " $B$ ", " $C$ ", figuras 06, 07, 10, 11, 14 e 15 em anexo). 


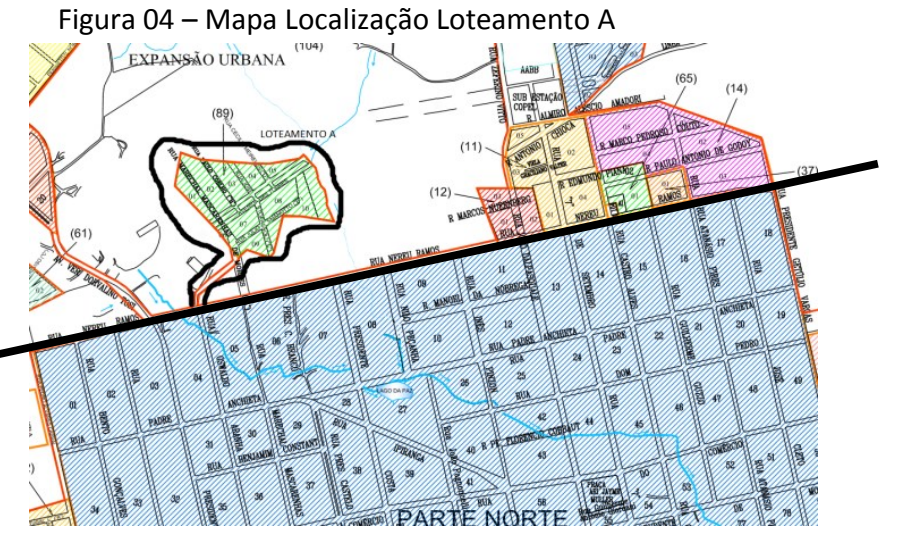

Fonte: doisvizinhos.pr.gov.br
Único acesso ao loteamento pela ligação da Rua Nereu Ramos.

Figura 05 - Imagem aérea localização Loteamento A

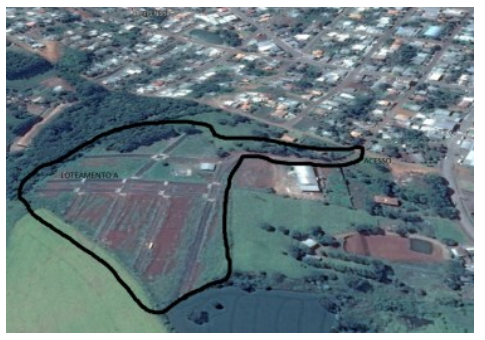

Fonte: google earth

Figura 06 - Loteamento $\mathrm{A}$

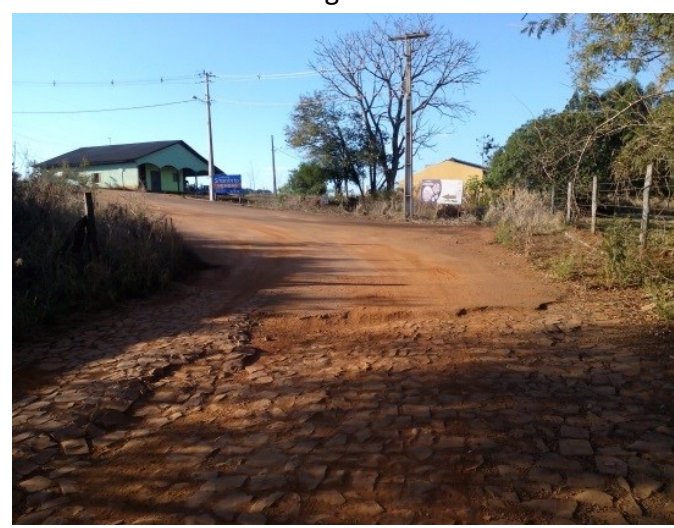

Fonte: a autora

Figura O8 - Mapa Localização Loteamento B e D

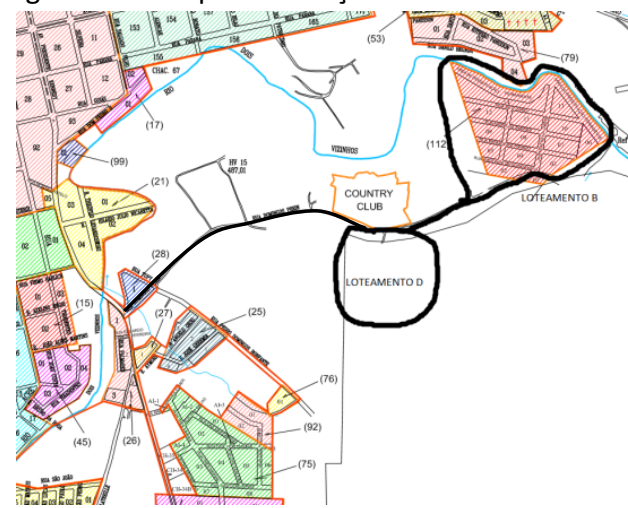

Fonte: doisvizinhos.pr.gov.br
Figura 09 - Mapa Aéreo localização Loteamento B

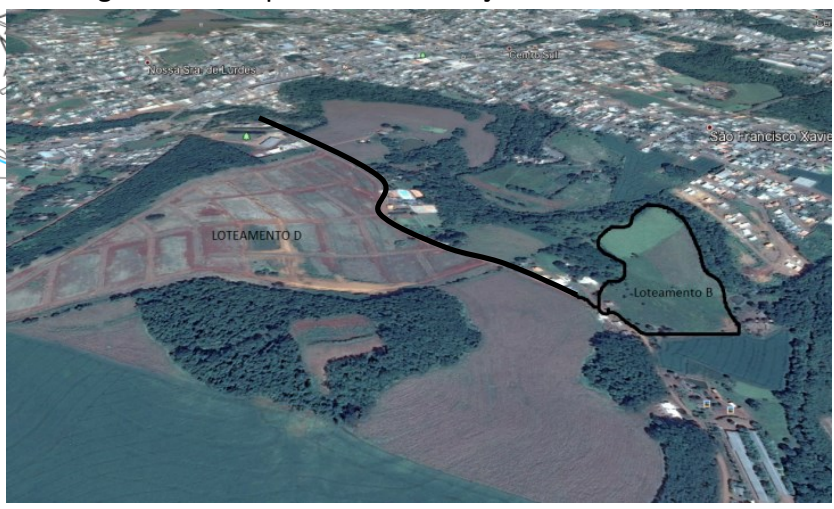

Fonte: google earth 


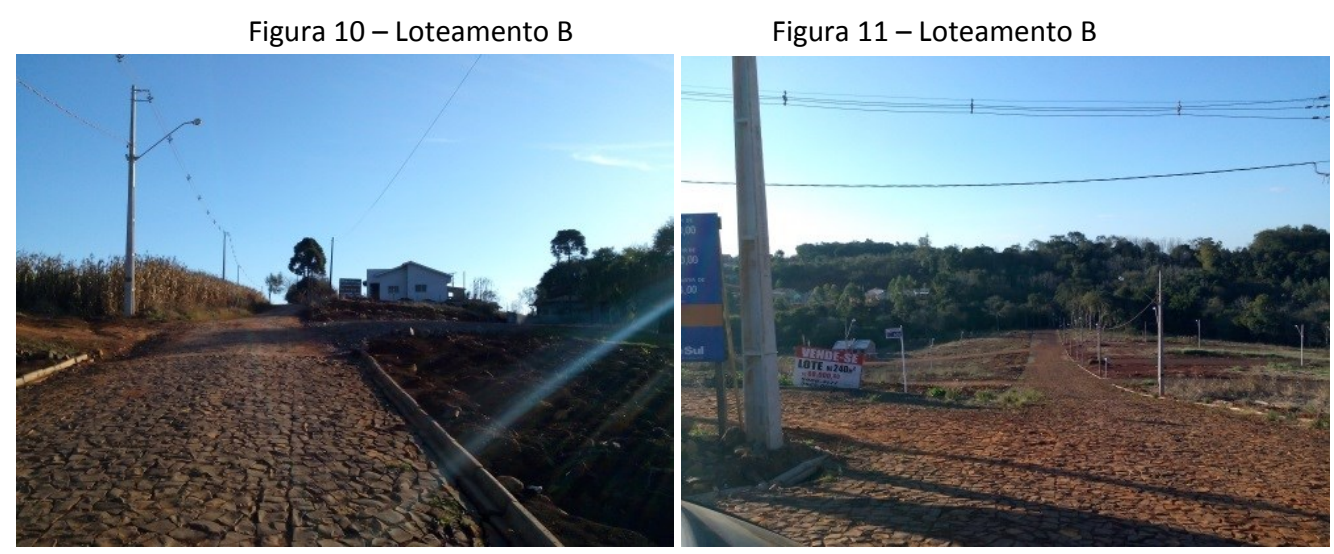

Fonte: a autora

Figura 12 - Mapa Localização Loteamento C

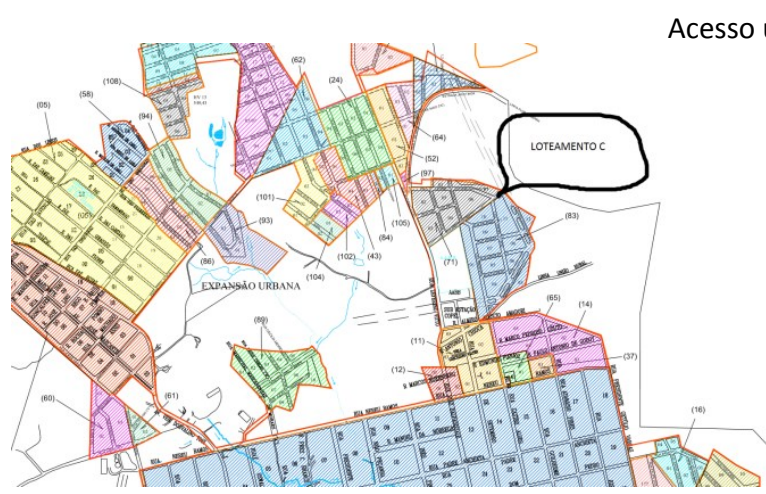

Fonte: doisvizinhos.pr.gov.br
Figura 13 - Mapa Aéreo localização Loteamento C

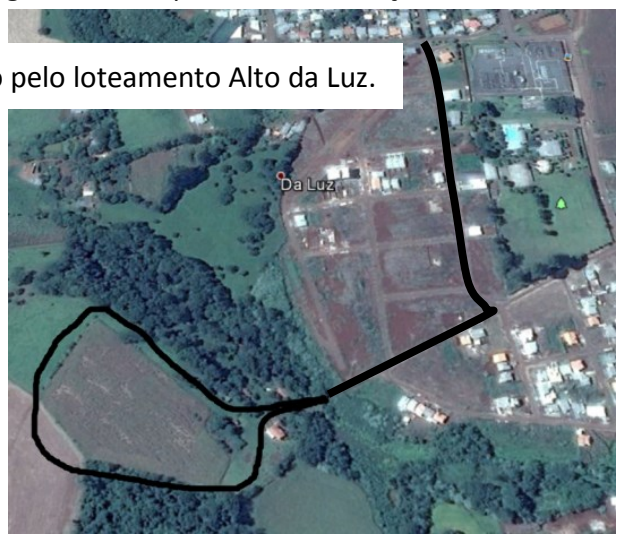

Fonte: google earth

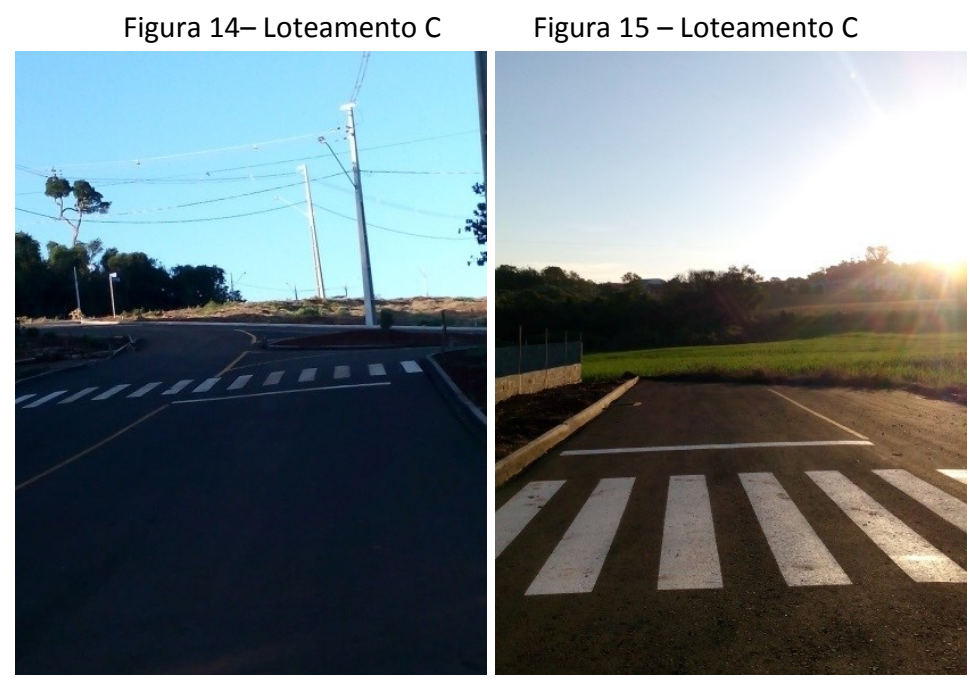

Fonte: a autora

Também não podemos deixar de observar a falta de cuidado existente no loteamento $C$, onde não foram observados a área de preservação permanente (APP), devendo deixar 30 metros da margem da mata para inicio de obras e loteamentos. Desta forma causa danos à natureza, não 


\section{Fórum Ambiental}

ISSN 1980-0827

da Alta Paulista

Volume 13, Número 1, 2017

tomando rumo para preservar recursos naturais ambientais para as futuras gerações. (Figura 15 e 16).

Figura 16 - Loteamento C

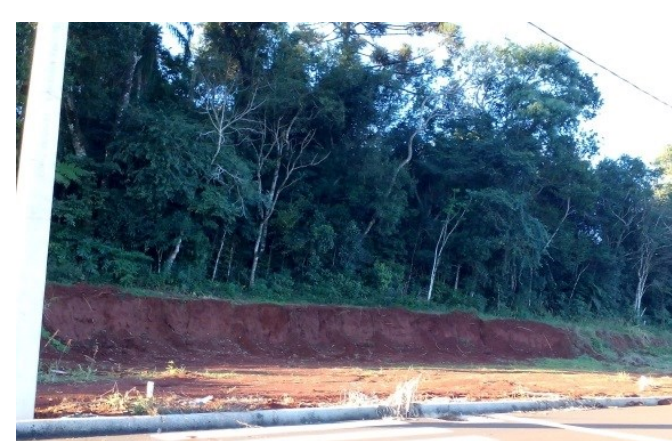

Fonte: a autora
Figura 17 - Loteamento C

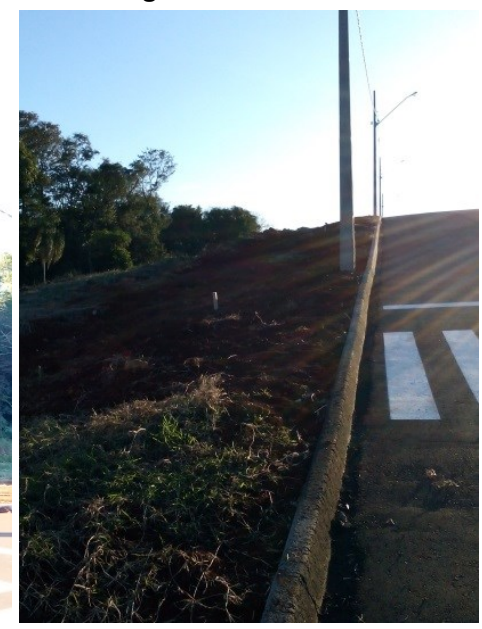

O loteamento " $D$ " foi considerado clandestino, tendo em vista ter realizado obras de parcelamentos de glebas sem autorização da prefeitura, mas está em processo de regularização que estão reformulando o referido. (Figuras 18 e 19)

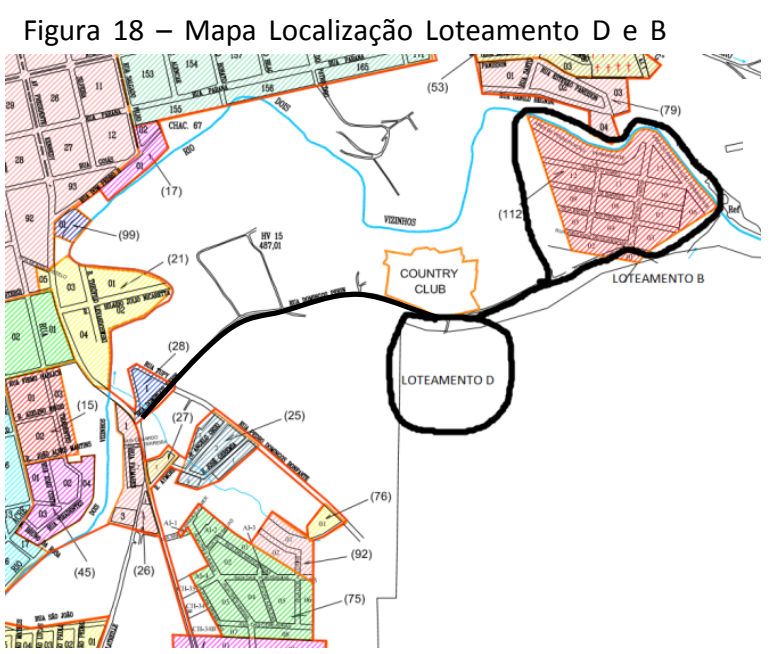

Fonte: doisvizinhos.pr.gov.br

Figura 20- Loteamento D
Figura 19 - Mapa Aéreo localização Loteamento D

Único acesso aos loteamentos $D$ e B

PR 281 KM 01. Saída sentido São Jorge, Pato Branco.

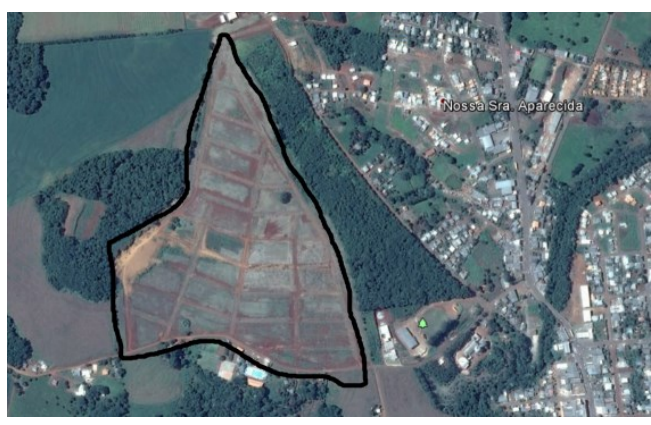

Fonte: google earth

Figura 21 - Loteamento D 


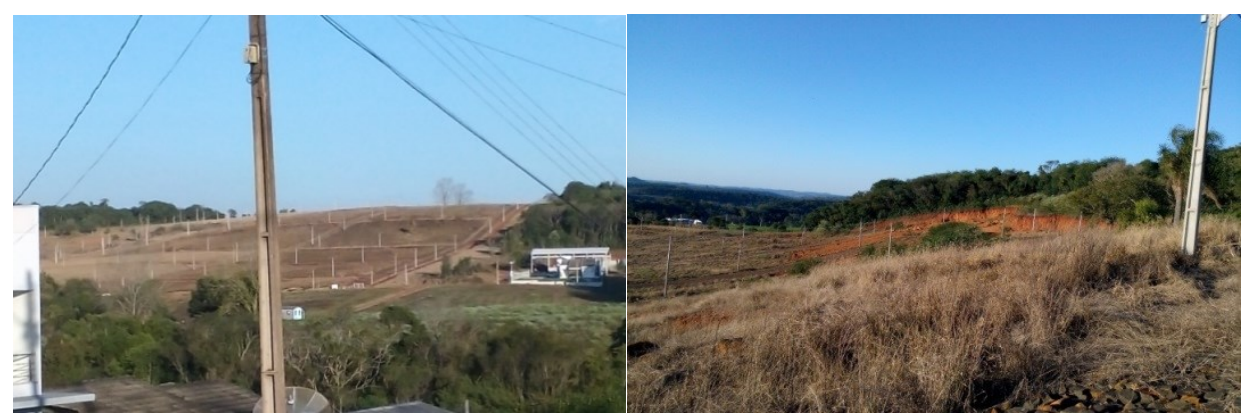

Fonte: a autora

Outro fator problemático encontrado nos loteamentos " $A$ ", " $B$ ", " $C$ " está distante das áreas de convívio/lazer da cidade, comércios ficam a grande distância, infraestrutura municipal ausente, um descaso com os proprietários dos lotes/moradias.

Para amenizar os impactos da integração da sociedade junto às áreas ambientais afetadas pela habitabilidade, seriam necessárias que fossem criados próximos a esses locais de APP's, áreas de convívio para os usuários da localidade para descanso, recreação e caminhadas, exercícios físicos.

Os lotes são dimensionados com área de $440,00 \mathrm{~m}^{2}$ para que sejam desmembrados, resultando em lotes menores possibilitando a venda para pessoas com menor poder aquisitivo.

Já, para solucionar o problema da entrada/saída única para os loteamentos, o loteador/empreendedor deverá realizar compra de mais terrenos existentes nas proximidades para alocar ao seu existente e realizar a sequência das ruas, inserindo nelas os acessos intermediários para maior acesso.

Nos loteamentos sem infraestrutura adequada, como falta de rede de esgoto, o loteador deve notificar a prefeitura para que regularize.

Por fim, nota-se que a implantação dos mesmos não foi desenvolvida pensando na topografia, mas sim na habitual forma de malha padrão utilizada por outros, tendo mais prejuízo nos solos quanto a erosões e desmoronamentos.

\section{CONSIDERAÇÕES FINAIS}

O estudo identificou que aspectos incorporam o desenvolvimento sustentável em parcelamentos de solos urbanos e quais são aplicados em Dois Vizinhos. Chegamos ao resultado que em poucas áreas são respeitadas as APP`s, concluindo que é necessário rever a legislação, as quais viabilizam o município como um idealizador de Desenvolvimento Sustentável.

Outra situação é a área de recreação ou implantação de praças. O loteador não envia uma proposta sugerindo um projeto para prefeitura, pois a rentabilidade é menor para ambos. Vale ressaltar que, com a criação destes ambientes traz gastos com a manutenção.

Os responsáveis pelas aprovações devem fazer cumprir as metas de tornar Dois Vizinhos em um referencial de Desenvolvimento Sustentável, conforme enunciado da lei 1311/2007 alterando o Plano Diretor da Cidade. 


\section{AGRADECIMENTOS}

Quero agradecer por tudo, pelos momentos em que vocês viveram carinhosamente e me fizeram sorrir, pelos momentos em que perdi a paciência, vocês vieram com palavras amenas e doces e me acalmaram.

Pelos momentos em que, meu coração estava em pedaços, vocês vieram cheios de amor e me curaram.

Pelos momentos de alegria, que fizeram questão de dividir comigo.

Pelos momentos que com muita esperança, pensaram junto comigo planejando meu futuro.

\section{REFERÊNCIAS}

FERNANDES. Aryane Gomes Vieira. As etapas para a aprovação do loteamento. Disponível em: http://www.fortes.adv.br/pt-BR/conteudo/artigos-e-noticias/303/as-etapas-para-a-aprovacao-doloteamento.aspx

MOTA. Seutônio. Urbanização e Meio Ambiente. Universidade de São Paulo.1999.

NEGREIROS. lara \& ABIKO. Alex Kenya. Diretrizes para Projetos de Loteamentos

Urbanos considerando os Métodos de Avaliação Ambiental. Disponivel em: http://www.pcc.usp.br/files/text/publications/BT_00526.pdf

SAMPAIO. Danusa Teodoro Sustentabilidade Urbana: Conceitos e Controvérsias. Universidade Federal de São Carlos. $2009 . \quad$ Disponível em: http://www.iau.usp.br/pesquisa/grupos/habis/biblioteca/digital/artigos/sustentabilidade/Artigo_ELECS 2009_Sustentabilidade\%20Urbana_conceitos\%20e\%20controversas_Sampaio.pdf

COMURB. Loteamento Sustentável para Sonhar e Viver. Campinas - SP. 2013. Disponível em: http://comurb.com.br/loteamento-sustentavel-para-sonhar-e-viver/

\section{BIBLIOGRAFIA CONSULTADA}

Brasil. Estatuto das Cidades. Lei 10.257/2001. Brasília. 2004. Disponível em:http://www.geomatica.ufpr.br/portal/wp-content/uploads/2015/03/Estatuto-da-Cidade.pdf

Dois Vizinhos. Lei 1529/2009. Parcelamento do Solo Urbano no Município de Dois Vizinhos. Disponível em: https://drive.google.com/folderview?id=0Bx5EHII-Fc1CNEhlbOhEMWlxLWc\&usp=drive_web

Prefeitura Municipal de Dois Vizinhos. Gestão Urbana. Disponível em: http://doisvizinhos.pr.gov.br/departamento-de-gestao-urbana/ 
REZENDE. Afonso Celso. F. \& MORETTI. Luiz Geraldo. Incorporação Imobiliária, Instituição de Condomínio e Loteaentos Urbanos, Campinas - SP. Editora Millenium, 2009.

www.teses.usp.br/teses/disponiveis/3/3146/tde...162710/.../DissertacaolaraNegreiros.pdf 